\title{
Per 7.5 Milliliters
}

National Cancer Institute

\section{Source}

National Cancer Institute. per 7.5 Milliliters. NCI Thesaurus. Code C122198.

A volume unit equal to 7.5 milliliters used as a denominator to build a derived unit expressed as a ratio. 